\title{
Ambulatory Blood Pressure Monitoring in the Elderly
}

\author{
Juan Diego Mediavilla García, ${ }^{1}$ Fernando Jaén Águila, ${ }^{1}$ Celia Fernández Torres, ${ }^{1}$ \\ Blas Gil Extremera, ${ }^{2}$ and Juan Jiménez Alonso ${ }^{1}$ \\ ${ }^{1}$ Hypertension Unit, Service of Internal Medicine, Virgen de las Nieves University Hospital, 18012 Granada, Spain \\ ${ }^{2}$ Hypertension Unit, Service of Internal Medicine, Clinic San Cecilio University Hospital, 18012 Granada, Spain
}

Correspondence should be addressed to Fernando Jaén Águila, fer0602@gmail.com

Received 11 July 2011; Accepted 8 September 2011

Academic Editor: Pedro Cía Gómez

Copyright ( $) 2012$ Juan Diego Mediavilla García et al. This is an open access article distributed under the Creative Commons Attribution License, which permits unrestricted use, distribution, and reproduction in any medium, provided the original work is properly cited.

The incidence of hypertension is high in the elderly and is present in $2 / 3$ of the patients older than 65 years. Prevalence can reach $90 \%$ in patients older than 80 years. The presence of isolated systolic hypertension (ISH) is characteristic of this population. However, the prevalence of hypertension by ambulatory blood pressure monitoring (ABPM) is not well known. In this study, we analyzed the special characteristics of hypertension in this population, giving special emphasis on ABPM readings.

\section{Introduction}

The incidence of hypertension is high in the elderly, and it is present in $2 / 3$ of the patients older than 65 years [1]. Prevalence can reach $90 \%$ in patients older than 80 years [2]. Systolic blood pressure (SBP) increases with age [3], and the presence of isolated systolic hypertension (ISH) is characteristic of this population. However, the prevalence of hypertension diagnosed by ambulatory blood pressure monitoring (ABPM) is not well known. The PROOF study [4] carried out in French patients aged older than 65 years showed that clinical blood pressure (CBP) was elevated in $58 \%$ of the patients, and $31 \%$ had diurnal SBP $>135 \mathrm{mmHg}$ by ambulatory monitoring. In this study, we analyzed the special characteristics of hypertension in this population, giving special emphasis on ABPM readings.

\section{Characteristics of Hypertension in the Elderly}

Ageing results in a decline in the cardiac output and cardiac frequency (beta-receptors-mediated response), as well as a trend towards ventricular hypertrophy, reduction of the left ventricular filling, renal plasma flux and renin plasma, and an increase in renal and peripheral resistances.

Ageing also produces an increase in arterial stiffness, a reduction of the compliance, and an increase in the pulse pressure; this, together with an increase in peripheral resistances, leads to ISH. Several systems are involved in the increase of peripheral resistances, such as reduction of beta2 receptors involved in vasodilation, or reduction in sodium ions, potassium and calcium ions, renin-angiotensin system, sympathetic nervous system, hormones, natriuretic factors, and endothelial factors. All this can explain the frequency of ISH, blood pressure (BP) variability, and the episodes of associated orthostatic hypotension. Old subjects present more frequently essential hypertension (except for renovascular secondary hypertension) and more severe target organ damage than the younger population. Hypertension affects subjects with a higher prevalence of ischemic heart disease, myocardial infarction, diastolic dysfunction, a tendency to arrhythmia and in general cerebral arteriosclerosis and peripheral arterial disease. There are also present other factors such as diabetes, and other concomitant diseases like pulmonary disease, depression, neoplasia, and so forht that should be considered when making diagnosis and treatment decisions.

\section{Normality Values}

Normality values of ABPM are based on several studies [5] (Table 1) on adult populations older than 65 years, despite that it is less represented by subjects aged 70-75 
TABLE 1: Blood pressure values in adults according to ABPM.

\begin{tabular}{lccc}
\hline & Optimal values & Normal values & High values \\
\hline Wake cycle & $<130 / 80$ & $<135 / 85$ & $>140 / 90$ \\
Sleep cycle & $<115 / 65$ & $<130 / 70$ & $>135 / 75$ \\
\hline
\end{tabular}

years or older. Published reports of patients older than 65 years showed mean daytime BP values ranging from $128 / 77 \mathrm{~mm} \mathrm{Hg}$ [6] to $140 / 78 \mathrm{~mm} \mathrm{Hg}$ in a UK study (including ambulatory and hospitalized patients), $134 / 81 \mathrm{~mm} \mathrm{Hg}$ in a healthy population $[7,8]$ in Germany, and values of $138 / 82 \mathrm{~mm} \mathrm{Hg}$ were found in patients aged 60-79 years and $147 / 83 \mathrm{~mm} \mathrm{Hg}$ in patients older than 80 years [9]. These values could be higher in diabetics or high vascular risk patients.

Therefore, normality values must be carefully studied in patients older than 80 years. It is not known yet the benefit of reducing clinical $\mathrm{BP}$ in this population group. Previous studies like HYVET, demonstrated a reduction in the mortality rate in 3.845 patients with SBP $>160 \mathrm{~mm} \mathrm{Hg}$, with the aim of reaching values of SBP $<150 \mathrm{~mm} \mathrm{Hg}$, but this study included patients with good physical and mental conditions, without previous cardiovascular disease, and only $7 \%$ of them were diabetics.

Bejan-Angoulvant et al. [10] carried out a meta-analysis in patients older than 80 years and demonstrated that intensive treatment reduced $35 \%$ of the risk of stroke, $50 \%$ of the risk of heart failure, and $27 \%$ of cardiovascular events, without differences in total mortality.

Evidences of reducing BP under $140 / 90 \mathrm{~mm} \mathrm{Hg}$ in old subjects has been recently discussed; however, any active treatment trial versus placebo therapy has been able to reduce SBP under $140 \mathrm{~mm} \mathrm{Hg}$ [11]. Therefore, there is no clinical evidence showing which are the normal $\mathrm{BP}$ values in old patients and even less by ABPM measurement.

\section{Isolated Systolic Hypertension}

ABPM data of patients with ISH are mainly reported in the SYST-EUR study [12], in patients older than 60 years with baseline clinical systolic blood pressure (CBP) values of 160$219 \mathrm{~mm} \mathrm{Hg}$ and diastolic BP values lower than $95 \mathrm{~mm} \mathrm{Hg}$. Patients were randomized and treated with nitrendipine (10$40 \mathrm{mg} / \mathrm{d})$ and the possible addition of enalapril $(5-20 \mathrm{mg} / \mathrm{d})$ according to $\mathrm{BP}$ values and/or hydrochlorothiazide $(12,5-$ $25 \mathrm{mg} / \mathrm{d}$ ) and were compared to placebo. SBP was associated with a poorer prognosis.

Clinical SBP of $160 \mathrm{~mm} \mathrm{Hg}$ was correlated with a 24h SBP monitoring of $142 \mathrm{~mm} \mathrm{Hg}, 145 \mathrm{~mm} \mathrm{Hg}$ for daytime $\mathrm{BP}$, and $132 \mathrm{~mm} \mathrm{Hg}$ for nighttime BP. Differences of the SBP between clinical and ambulatory BP measurement were higher in old subjects (Figure 1).

A study [13] carried out in 578 patients aged older than 70 years demonstrated not only the predictive capacity of ABPM with respect to cardiovascular morbidity but also the capacity to diagnose hypertensive patients with normal BP values at the doctor's office.
Today, the US and European consensus for ABPM agrees that ABPM measures are important in children and old people, since CBP does not reflect accurately real BP values in these population groups [14]. This is very important to control antihypertensive therapy and establish the most adequate treatment.

\section{Pulse Pressure and Arterial Distensibility}

Both conditions are more frequently found altered in older ages. It is well known that pulse pressure (PP) is an independent cardiovascular risk factor especially present in old subjects $[15,16]$ as a result of a decline in left ventricular ejection, arterial distensibility, and reflected wave velocity. ABPM is a better estimate of PP than CBP. SYST-EUR analyzed PP by ABPM in 808 patients.

In the placebo group, 24-h and nighttime PP was predictive of total and cardiovascular mortality, stroke, and cardiac events. Daytime PP was a predictor of cardiovascular mortality, all cardiovascular events, and stroke. The hazard rates for $10 \mathrm{~mm} \mathrm{Hg}$ rise was from 1.25 to 1.68 ; however, conventional measurement of pulse pressure was 1.35. No significant differences were found in the active treatment group.

Staessen et al. [17] reported that PP estimated by ABPM was a better predictor of events than that measured using CBP in old people with ISH.

In the PIUMA study [18], ABPM values were observed in 2010 untreated hypertensive patients. In this study 24-h PP distribution into terciles was associated with an increase in cardiovascular mortality of 1.19, 1.81, and 4.92 after adjustment for other risk factors. It is suggested that 24-h PP is a good predictor especially when values are higher than $53 \mathrm{~mm} \mathrm{Hg}$. Later, in a 3.8-year follow-up study [19] carried out in patients older than 60 years, the highest SBP and PP and lower DBP were correlated with mortality. A median nighttime PP of $78 \mathrm{~mm} \mathrm{Hg}$ of the 4th quartile showed a 4.4 times greater risk when compared with the first quartile of PP.

However, Masahiro et al., in a study carried out in 1542 Ohasama residents, found that the ambulatory arterial stiffness index (AASI) and PP were reliable to measure arterial stiffness and to predict vascular mortality, although PP when adjusted for age and gender was less efficient in the prognostic value of vascular events of the ABMP or AASI [20].

Arterial distensibility can be measured indirectly by pulse wave velocity, which is altered with age. Asmar et al. [21] found a good correlation between ABPM and arterial distensibility; therefore, ABPM could provide indirectly a reliable assessment of arterial distensibility. 

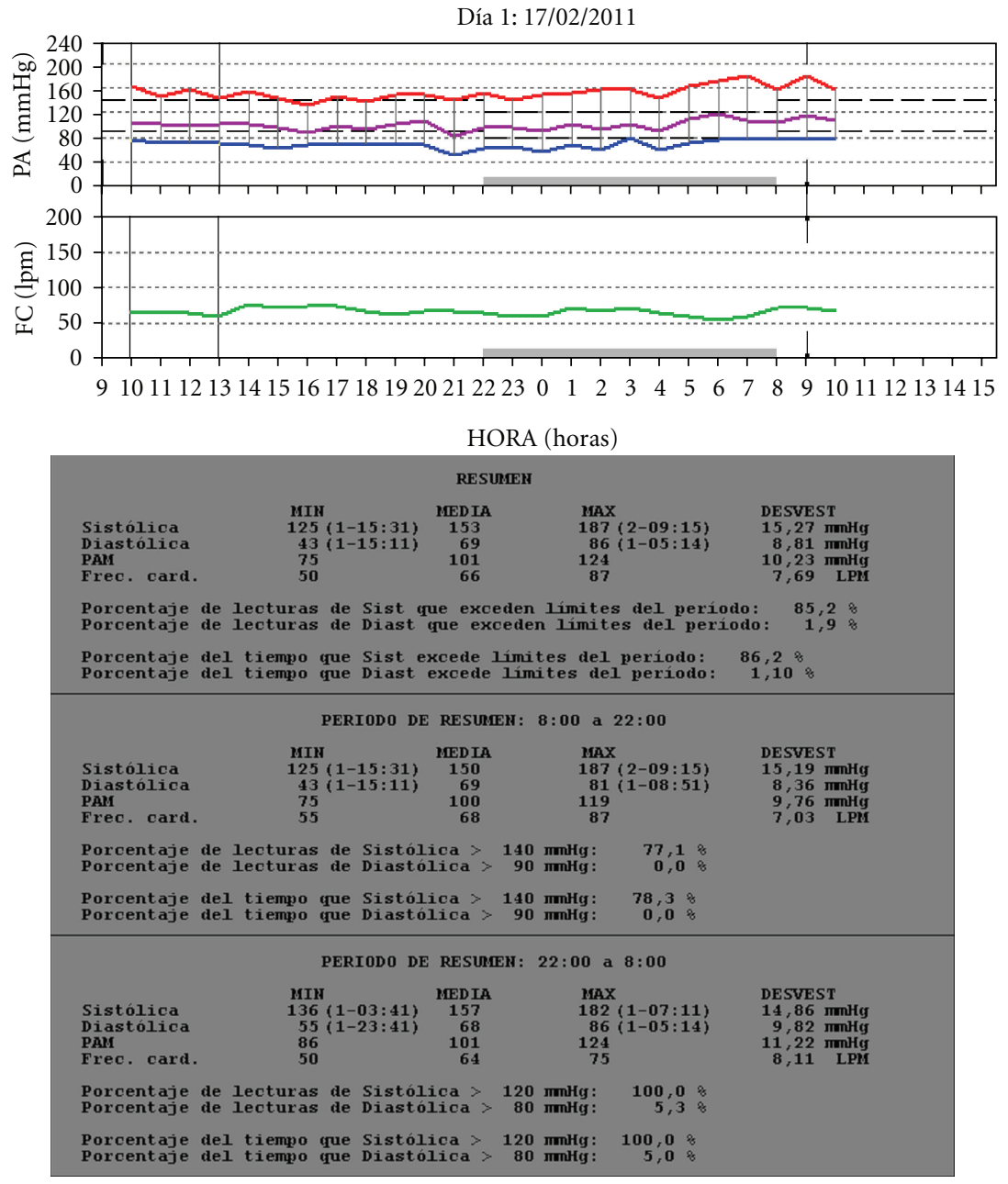

FIgURE 1: Patient aged 78 years with isolated systolic hypertension and riser pattern.

\section{Nighttime Systolic Blood Pressure}

Nighttime SBP is becoming more and more important, as reported in the SYST-EUR study [12] or HOPE substudy [22] in which the effect of nighttime administration of ramipril produced a significant fall $(17 / 8 \mathrm{~mm} \mathrm{Hg})$ in nighttime BP values, not appreciated in CBP measurement. In an Anglo-Scandinavian cardiac outcomes trial substudy (ASCOT) [23] carried out in patients with a mean age of 63 years, nighttime SBP was a predictor of vascular events. The decrease in nighttime SBP was higher in the amlodipineperindopril group than in the atenolol-thiazide group without differences in the daytime BP values. The differences found in the nighttime BP could explain the higher benefit obtained in the amlodipine-perindopril group. DUBLIN study [24] analzed the relationship between CBP, ABPM, and mortality in 1144 patients aged older than 65 years, and found that nighttime SBP was the best correlated, with a risk ratio estimation of $1.18(1.11-1.25, P<0.001)$.

\section{Hypotension}

Orthostatic hypotension can occur at any age; however, it is more frequent in the elderly. It is defined as a decrease in the SBP of at least $20 \mathrm{~mm} \mathrm{Hg}$ or a decrease in the DBP of $10 \mathrm{~mm} \mathrm{Hg}$ in the orthostatic position 3 minutes after BP measurement in the supine position [25]. It is generally associated with dizziness, slight sweating, and sometimes it is asymptomatic. ABPM is a better predictor of these events than CBP [26]. Many of these events are related to medication (diuretics and beta blockers), diabetes, or disautonomy (baroreceptors) and are more frequently found in the elderly.

Postprandial hypotension is more frequently found in old subjects [27] and is defined as a decrease in SBP of more than $20 \mathrm{~mm} \mathrm{Hg}$ up to 1 hour after eating, without alteration of heart rate. Postprandial hypotension has been reported as predictor of mortality in some studies [28, 29]. Figure 2 shows the ABPM readings of an old subject with hypotension episodes.

\section{White-Coat Hypertension}

The white-coat effect occurs when CBP is temporary elevated in the clinical setting but not at home. This phenomenon was described by Scipione Riva-Rocci in 1897, but it was really studied in the clinical setting after the introduction of 


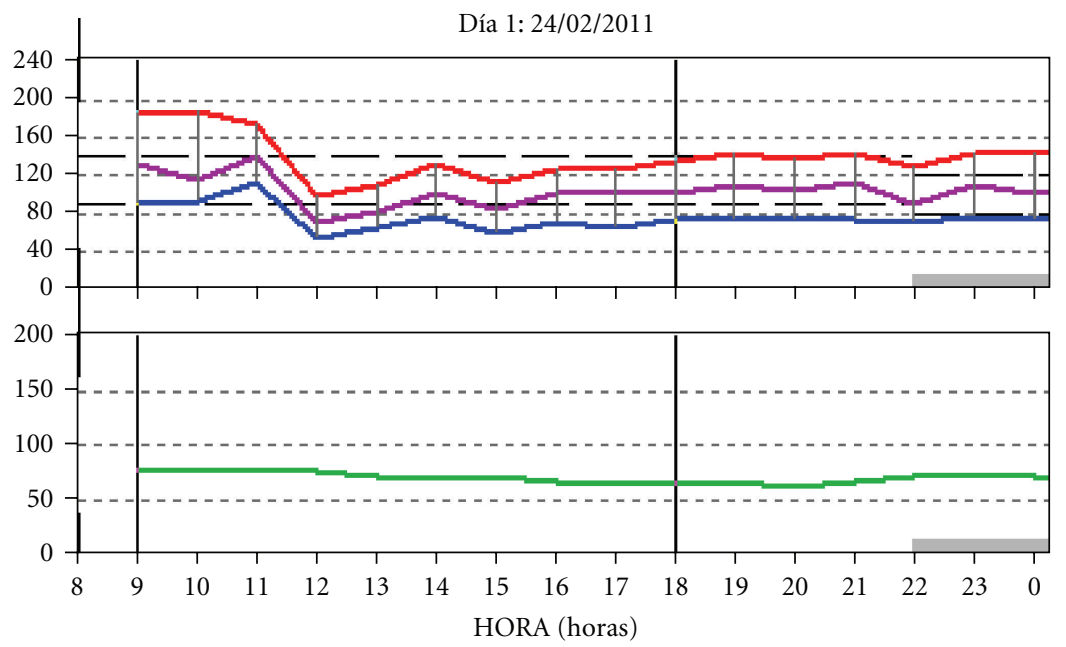

FIgURe 2: Patient of 79 years old with hypertension and diabetes. Combined therapy with 4 antihypertensive agents. Hypotensive episodes.

ABPM. Its prognostic significance is not yet clear. In some studies [30-32] mortality rate was 2 or 3 times higher, and it was considered an independent factor for left ventricular mass hypertrophy, increase of arteriosclerosis, or increase in carotid intima-media. Other authors [33,34] think that white-coat hypertension ( $\mathrm{WCH}$ ) does not correlate with organ damage or cardiovascular events. Age was found to be an independent and common factor influencing WCH in the multivariate analysis of different studies [35-37]. WCH clearly increases with age. In old patients with ISBP [38] the effect of SBP reached $21 \mathrm{~mm} \mathrm{Hg}$. These authors reported that the elevation of CSBP in untreated old patients is the main factor to suspect white-coat effect.

\section{Masked Hypertension}

Masked hypertension is defined as a normal blood pressure (BP) in the clinic or office $(<140 / 90 \mathrm{~mm} \mathrm{Hg})$, but an elevated $\mathrm{BP}$ out of the clinic (ambulatory daytime BP or home BP $>135 / 85 \mathrm{~mm} \mathrm{Hg}$ ) [39]. Its prevalence is not well known, but it has been suggested to be about $10-20 \%$ of the general population $[40,41]$. It is well known that it is associated with a more severe lesion of the target organ [42-44] and cardiovascular events [13, 45]. It seems that $\mathrm{MH}$ is not more frequent in old patients. Bobrie et al. [46] in a study carried out in 4939 patients older than 65 years, reported a prevalence of $\mathrm{MH}$ of $9.4 \%$, with $\mathrm{CBP}$ $<140 / 90 \mathrm{~mm} \mathrm{Hg}$ for office BP and 135/85 mm Hg for home BP. In fact, it has been suggested that masked hypertension must be suspected in smoker young men, with unhealthy lifestyle, high vascular risk, diabetics, presence of renal disease with proteinuria, daytime hyperactivity, and patients with transient hypertension [47].

\section{Circadian Blood Pressure Patterns}

ABPM allows knowing BP absolute values and gives information about circadian BP rhythm. According to these patterns, patients are classified as dipper (a decrease of BP at night $>10 \%$ ), nondipper (BP decrease $<10 \%$ ), extreme dipper (BP decrease $>20 \%$ ), and riser pattern (an elevation of $\mathrm{BP}$ at night). There are increasing evidences that nondipper pattern is associated with a poorer cardiovascular prognosis $[48,49]$, which has been reported by Staessen et al. [12] in old patients with ISH. Other authors reported that the nondecrease of BP at night is related to the degree of concurrent lesion of the target organ, severity of cardiovascular disease, and alterations in sleep quality [50].

Patients with a lower decrease of $\mathrm{BP}$ at night due to insomnia do not seem to present a poorer vascular prognosis, or, if so, it is not related to the nondipping pattern but probably due to a higher value of nocturnal BP [51]. Sleep quality alterations are more frequent in the elderly; therefore, the circadian pattern in these patients must be carried out more carefully. The 24-hour diary to record daily ABPM is indispensable in these patients to adjust the sleep-wake cycle.

A prevalence of $25-35 \%$ of the nondipping pattern was observed in the general population. A Spanish study [52] carried out in 42,947 patients showed a nondipping pattern of $41 \%$, which reached $53 \%$ in treated hypertensive patients. This pattern can reach up to $60 \%$ in high-risk patients [53]. It must be remembered that old patients present higher levels of SBP and a higher vascular risk, target organ damage, diabetes, renal disease, or associated disease, all of them being related to the nondipping pattern [52]. Generally, the loss of the circadian pattern with a lower decrease of nocturnal BP is associated with age, both in men [54] and very old women [7], and in centenarian patients $[8,55]$.

The morning elevation of BP is also important $[42,56]$. Kario et al. [57] in a study carried out in old patients found a clear correlation between lesions in the white substance and the morning elevation of BP, independently of the absolute values of BP.

Further studies are needed in order to determine whether morning elevation of BP is especially relevant in the old population. 
TABLE 2: Studies published on ABPM in subjects older than 65 years.

\begin{tabular}{|c|c|c|c|c|}
\hline Study (year) & $\begin{array}{l}\text { No. of } \\
\text { patients }\end{array}$ & Age range & Time of followup & Results \\
\hline Lee et al. (1995) [8] & 102 & $65-93$ & $\mathrm{NA}$ & Normality values \\
\hline Fotherby and Potter (1995) [7] & 108 & $65->80$ & NA & $\begin{array}{l}\text { Normotensive values of ABPM } \\
\text { Nondipping pattern }\end{array}$ \\
\hline Sega et al. (1997) [6] & 800 & $65-74$ & NA & Population base. Normality values \\
\hline Hoshide (2002) [67] & 811 & & 41 months & $\begin{array}{l}\text { ABPM was more useful than CB P } \\
\text { in extreme dipper and riser patterns }\end{array}$ \\
\hline Wing (2002) [68] & 713 & $65-83$ & N/A & ABPM prevents overtreatment \\
\hline O'Sullivan et al. (2003) [9] & 156 & 78 & NA & $\begin{array}{l}\text { SBP was associated with age } \\
\text { Nondipping pattern and age }\end{array}$ \\
\hline Björklund et al. (2004) [13] & 872 (men) & 70 & $9.5 \mathrm{yrs}$ & Prognosis of cardiovascular risk \\
\hline Burr et al. (2008) [24] & 1144 & 72 & $6.7 \mathrm{yrs}$ & $\begin{array}{l}\text { ABPM as mortality predictor. } \\
\text { Nighttime SBP as best predictor }\end{array}$ \\
\hline Ungar et al. (2009) [19] & 805 & 72 & $3.8 \mathrm{yrs}$ & $\begin{array}{l}\text { SBP, PP with low DBP, and } \\
\text { mortality }\end{array}$ \\
\hline Gosse et al. (2010) [4] & 955 & $>65$ & N/A & $\begin{array}{l}\text { Population base. Prevalence of } \\
\text { hypertension }\end{array}$ \\
\hline Andrade et al. (2010) [62] & 106 & 83 & 30 months & $\begin{array}{l}\text { ABPM predicts cardiovascular } \\
\text { events. SBP loads }\end{array}$ \\
\hline
\end{tabular}

NA: not applicable.

Diurnal and nocturnal BP variability (defined by quantification of SD of mean BP) is associated with an increased cardiovascular risk, left ventricular mass, and progression of carotid intima-media thickness $[58,59]$. Mediavilla García et al. [60] reported a significant relationship between BP variability, age, and glomerular filtration. In the PIUMA study [61] cardiovascular morbidity was associated with BP variability and age. In a SYST-EUR substudy of 744 old patients, which analzed BP variability in $24 \mathrm{~h}$, daytime, and nighttime, nocturnal BP variability of $5 \mathrm{~mm} \mathrm{Hg}$ was associated with an increased risk of cardiovascular event of $80 \%$ with respect to the placebo group.

\section{Blood Pressure in Very Old Subjects}

Although several studies have reported the relationship between ABPM and cardiovascular risk in the elderly (Table 2), few studies have been published on subjects older than 80 years. Generally these studies $[7,9,55]$ are carried out in patient samples with a different population base too small to obtain valid conclusions; however, in this population subset older than 80 years, SBP by ambulatory measurement was higher than that of the subgroup of younger patients. Andrade et al. [62] recently studied 126 patients with a mean age of 83.8 years. The variables associated with the number of cardiovascular events during followup were patients with a clinical history of cerebrovascular event and higher diurnal SBP values.

\section{High Blood Pressure and Dementia}

Dementia from all causes has a prevalence of about $8 \%$ of the population over 65 years. Between 15 and $30 \%$ of these cases are vascular. In the elderly, subcortical small vessel disease is known to be associated with vascular dementia. Mild cognitive impairment (MCI) is described as a transition phase between healthy cognitive aging and dementia.

This concept facilitated case identification in early stage, and its progression may be preventable through modification of vascular risk factors as hypertension.

The SYST-EUR study [12] showed that a decrease of $7 \mathrm{~mm} \mathrm{Hg}$ in SBP and $3,2 \mathrm{~mm} \mathrm{Hg}$ in DBP over 3,9 years will reduce significantly the incidence of dementia. In the Women's Health Initiative Memory Study (WHIMS, [63]), the cognitive function of 7.149 women aged $>65$ years was assessed using the modified minimental state examination. During a follow-up period of 4,5 years, women with hypertension appeared to be at greater risk of dementia or MCI. Based on these studies, hypertension is associated with the development of MCI and dementia.

ABPM has been shown to provide a better predictive value for cardiovascular events than clinic BP. Recent studies have shown that ambulatory BP variation is associated with cognitive function. High nocturnal SBP level [64], Nondipper status [65], and exaggerated BP variability are suggested to be significant determinants of cognitive impairment. In addition, 24-hour SBP has been shown to be a independent factor for brain atrophy in the elderly [66]. So an strict BP control, including nighttime, may have a neuroprotective effect and prevent the incidence of dementia. The recent literature support that ABPM would help us in an earlier diagnosis of MCI.

\section{Conclusions}

In conclusion, there are many reasons to recommend ABPM in hypertensive old patients, such as ISBP, differences 
between clinical and ambulatory $\mathrm{BP}, \mathrm{PP}$, magnitude of the white-coat effect, assessment of orthostatic hypotension values and its relationship with the patient medication, nighttime hypertension, mild cognitive impairment and BP variability. These important variables demonstrate that just the fact of being an aged patient is a sufficient reason to perform ABPM. We support that the diagnosis of hypertension by ABPM may have substantial clinical and epidemiological implications.

Even so, further studies are needed to demonstrate the importance of ABPM values in the study of the morbidity and mortality in these patients.

\section{Abbreviations}

\begin{tabular}{|c|c|}
\hline HORA: & Hours \\
\hline PA: & $\mathrm{BP}$ \\
\hline FC: & $\mathrm{HR}$ \\
\hline LPM: & BPM \\
\hline Dia 1: & Day 1 \\
\hline Horas: & Time (hours) \\
\hline Sistólica: & SBP \\
\hline Diastólica: & DBP \\
\hline PAM: & $\mathrm{M} \mathrm{BP}$ \\
\hline Frec. Card: & HR \\
\hline MIN: & Minimum \\
\hline MEDIA: & Mean \\
\hline MAX: & Maximum \\
\hline DESVEST SD: & Standard deviation \\
\hline Lpm: & bpm (beats per minute) \\
\hline $\begin{array}{l}\text { Porcentaje de lecturas de } \\
\text { sist que exceden limites } \\
\text { del periodo: }\end{array}$ & $\begin{array}{l}\text { Percentage of SBP readings of } \\
\text { the period }\end{array}$ \\
\hline $\begin{array}{l}\text { Porcentaje de lecturas de } \\
\text { diastolica que exceden } \\
\text { limites del periodo: }\end{array}$ & $\begin{array}{l}\text { Percentage of DBP readings of } \\
\text { the period }\end{array}$ \\
\hline $\begin{array}{l}\text { Porcentage del tiempo } \\
\text { que diastólica excede } \\
\text { limites del period: }\end{array}$ & $\begin{array}{l}\text { Time percentage of SBP } \\
\text { readings. }\end{array}$ \\
\hline
\end{tabular}

\section{References}

[1] Guidelines Committee, "2003 European Society of Hypertension/European Society of Cardiology guidelines for the management of arterial hypertension," Journal of Hypertension, vol. 21, pp. 1011-1053, 2003.

[2] Y. Wang and Q. J. Wang, "The prevalence of prehypertension and hypertension among US adults according to the new joint nacional committee guidelines: new challenges of the old problem," Archives of Internal Medicine, vol. 164, no. 19, pp. 2126-2134, 2004.

[3] V. L. Burt, P. Whelton, E. J. Roccella et al., "Prevalence of hypertension in the US adult population: results from the Third National Health and Nutrition Examination Survey, 1988-1991," Hypertension, vol. 25, no. 3, pp. 305-313, 1995.

[4] P. Gosse, V. Dauphinot, F. Roche, V. Pichot, S. Celle, and J. C. Barthelemy, "Prevalence of clinical and ambulatory hypertension in a population of 65-year-olds: the PROOF study," Journal of Clinical Hypertension, vol. 12, no. 3, pp. 160$165,2010$.
[5] E. O'Brien, R. Asmar, L. Beilin et al., "Practice guidelines of the European Society of Hypertension for clinic, ambulatory and self blood pressure measurement," Journal of Hypertension, vol. 23, no. 4, pp. 697-701, 2005.

[6] R. Sega, G. Cesana, C. Milesi, G. Grassi, A. Zanchetti, and G. Mancia, "Ambulatory and home blood pressure normality in the elderly: data from the PAMELA population," Hypertension, vol. 30, no. 1, pp. 1-6, 1997.

[7] M. D. Fotherby and J. F. Potter, "Twenty-four-hour ambulatory blood pressure in old and very old subjects," Journal of Hypertension, vol. 13, no. 12, pp. 1742-1746, 1995.

[8] D. R. Lee, C. G. Swift, and S. H. D. Jackson, "Twenty-fourhour ambulatory blood pressure monitoring in healthy elderly people: reference values," Age and Ageing, vol. 24, no. 2, pp. 91-95, 1995.

[9] C. O'Sullivan, J. Duggan, N. Atkins, and E. O'Brien, “Twentyfour-hour ambulatory blood pressure in community-dwelling elderly men and women, aged 60-102 years," Journal of Hypertension, vol. 21, no. 9, pp. 1641-1647, 2003.

[10] T. Bejan-Angoulvant, M. Saadatian-Elahi, J. M. Wright et al., "Treatment of hypertension in patients 80 years and older: the lower the better? A meta-analysis of randomized controlled trials," Journal of Hypertension, vol. 28, no. 7, pp. 1366-1372, 2010.

[11] A. Zanchetti, G. Grassi, and G. Mancia, "When should antihypertensive drug treatment be initiated and to what levels should systolic blood pressure be lowered? A critical reappraisal," Journal of Hypertension, vol. 27, no. 5, pp. 923934, 2009.

[12] J. A. Staessen, L. Thijs, R. Fagard et al., "Predicting cardiovascular risk using conventional vs ambulatory blood pressure in older patients with systolic hypertension," Journal of the American Medical Association, vol. 282, no. 6, pp. 539-546, 1999.

[13] K. Björklund, L. Lind, B. Zethelius, B. Andrén, and H. Lithell, "Isolated ambulatory hypertension predicts cardiovascular morbidity in elderly men," Circulation, vol. 107, no. 9, pp. 1297-1302, 2003.

[14] G. Parati and T. G. Pickering, "Home blood-pressure monitoring: US and European consensus," The Lancet, vol. 373, no. 9667, pp. 876-878, 2009.

[15] J. Blacher, J. A. Staessen, X. Girerd et al., "Pulse pressure not mean pressure determines cardiovascular risk in older hypertensive patients," Archives of Internal Medicine, vol. 160, no. 8, pp. 1085-1089, 2000.

[16] S. S. Franklin, S. A. Khan, N. D. Wong, M. G. Larson, and D. Levy, "Is pulse pressure useful in predicting risk for coronary heart disease? The Framingham Heart Study," Circulation, vol. 100, no. 4, pp. 354-360, 1999.

[17] J. A. Staessen, R. Asmar, M. De Buyzere et al., "Task force II: blood pressure measurement and cardiovacular outcome," Blood Pressure Monitoring, vol. 6, no. 6, pp. 355-370, 2001.

[18] P. Verdecchia, "Prognostic value of ambulatory blood pressure: current evidence and clinical implications," Hypertension, vol. 35, no. 3, pp. 844-851, 2000.

[19] A. Ungar, G. Pepe, L. Lambertucci et al., "Low diastolic ambulatory blood pressure is associated with greater all-cause mortality in older patients with hypertension," Journal of the American Geriatrics Society, vol. 57, no. 2, pp. 291-296, 2009.

[20] K. Masahiro, J. A. Staessen, O. Takayoshi et al., "Ambulatory arterial stiffness index and 24-hour ambulatory pulse pressure as predictors of mortality in Ohasama, Japan," Stroke, vol. 38, no. 4, pp. 1161-1166, 2007.

[21] R. G. Asmar, P. C. Brunel, B. M. Pannier, P. J. Lacolley, and M. E. Safar, "Arterial distensibility and ambulatory blood pressure 
monitoring in essential hypertension," The American Journal of Cardiology, vol. 61, no. 13, pp. 1066-1070, 1988.

[22] P. Svensson, U. de Faire, P. Sleight, S. Yusuf, and J. Östergren, "Comparative effects of ramipril on ambulatory and office blood pressures: a HOPE substudy," Hypertension, vol. 38, no. 6, pp. 28-32, 2001.

[23] E. Dolan, A. V. Stanton, S. Thom et al., "Ambulatory blood pressure monitoring predicts cardiovascular events in treated hypertensive patients-an Anglo-Scandinavian cardiac outcomes trial substudy," Journal of Hypertension, vol. 27, no. 4, pp. 876-885, 2009.

[24] M. L. Burr, E. Dolan, E. W. O’Brien, E. T. O’Brien, and P. McCormack, "The value of ambulatory blood pressure in older adults: the Dublin outcome study," Age and Ageing, vol. 37, no. 2, pp. 201-206, 2008.

[25] A. V. Chobanian, G. L. Bakris, H. R. Black et al., "Seventh report of the Joint National Committee on prevention, detection, evaluation, and treatment of high blood pressure," Hypertension, vol. 42, no. 6, pp. 1206-1252, 2003.

[26] R. J. Marchiando and M. P. Elston, "Automated ambulatory blood pressure monitoring: clinical utility in the family practice setting," American Family Physician, vol. 67, no. 11, pp. 2343-2350, 2003.

[27] C. J. Mathias, "Postprandial hypotension: pathophysiological mechanisms and clinical implications in different disorders," Hypertension, vol. 18, no. 5, pp. 694-704, 1991.

[28] W. S. Aronow and C. Ahn, "Association of postprandial hypotension with incidence of falls, syncope, coronary events, stroke, and total mortality at 29-month follow-up in 499 older nursing home residents," Journal of the American Geriatrics Society, vol. 45, no. 9, pp. 1051-1053, 1997.

[29] A. A. Fisher, M. W. Davis, W. Srikusalanukul, and M. M. Budge, "Postprandial hypotension predicts all-cause mortality in older, low-level care residents," Journal of the American Geriatrics Society, vol. 53, no. 8, pp. 1313-1320, 2005.

[30] T. E. Strandberg and V. Salomaa, "White coat effect, blood pressure and mortality in men: prospective cohort study," European Heart Journal, vol. 21, no. 20, pp. 1715-1719, 2000.

[31] P. Palatini, M. Penzo, C. Canali, F. Dorigatti, and A. C. Pessina, "Interactive action of the white-coat effect and the blood pressure levels on cardiovascular complications in hypertension," The American Journal of Medicine, vol. 103, no. 3, pp. 208-216, 1997.

[32] T. Nakashima, S. Yamano, R. Sasaki et al., "White-coat hypertension contributes to the presence of carotid arteriosclerosis," Hypertension Research, vol. 27, no. 10, pp. 739-745, 2004.

[33] P. Lantelme, H. Milon, M. Vernet, and C. Gayet, "Difference between office and ambulatory blood pressure or real white coat effect: does it matter in terms of prognosis?" Journal of Hypertension, vol. 18, no. 4, pp. 383-389, 2000.

[34] P. Verdecchia, G. Schillaci, C. Borgioni, A. Ciucci, and C. Porcellati, "Prognostic significance of the white coat effect," Hypertension, vol. 29, no. 6, pp. 1218-1224, 1997.

[35] G. A. Mansoor, E. J. McCabe, and W. B. White, "Determinants of the white-coat effect in hypertensive subjects," Journal of Human Hypertension, vol. 10, no. 2, pp. 87-92, 1996.

[36] M. Lindbæk, E. Sandvik, K. Liodden, J. Mjell, and K. Ravnsborg-Gjertsen, "Predictors for the white coat effect in general practice patients with suspected and treated hypertension," British Journal of General Practice, vol. 53, no. 495, pp. 790-793, 2003.

[37] E. D. Manios, E. A. Koroboki, G. K. Tsivgoulis et al., "Factors influencing white-coat effect," American Journal of Hypertension, vol. 21, no. 2, pp. 153-158, 2008.
[38] L. Thijs, A. Amery, D. Clement et al., “Ambulatory blood pressure monitoring in elderly patients with isolated systolic hypertension," Journal of Hypertension, vol. 10, no. 7, pp. 693699, 1992.

[39] T. G. Pickering, K. Davidson, W. Gerin, and J. E. Schwartz, "Masked hypertension," Hypertension, vol. 40, no. 6, pp. 795796, 2002.

[40] Y. Kawano, T. Horio, T. Matayoshi, and K. Kamide, "Masked hypertension: subtypes and target organ damage," Clinical and Experimental Hypertension, vol. 30, no. 3-4, pp. 289-296, 2008.

[41] T. G. Pickering, K. Eguchi, and K. Kario, "Masked hypertension: a review," Hypertension Research, vol. 30, no. 6, pp. 479488, 2007.

[42] J. E. Liu, M. J. Roman, R. Pini, J. E. Schwartz, T. G. Pickering, and R. B. Devereux, "Cardiac and arterial target organ damage in adults with elevated ambulatory and normal office blood pressure," Annals of Internal Medicine, vol. 131, no. 8, pp. 564$572,1999$.

[43] R. Sega, G. Trocino, A. Lanzarotti et al., "Alterations of cardiac structure in patients with isolated office, ambulatory, or home hypertension: data from the general population (Pressione Arteriose Monitorate E Loro Associazioni [PAMELA] Study)," Circulation, vol. 104, no. 12, pp. 1385-1392, 2001.

[44] G. Schillaci, P. Verdecchia, N. Sacchi et al., "Clinical relevance of office underestimation of usual blood pressure in treated hypertension," American Journal of Hypertension, vol. 13, no. 5, pp. 523-528, 2000.

[45] T. Ohkubo, M. Kikuya, H. Metoki et al., "Prognosis of "masked" hypertension and "white-coat" hypertension detected by 24-h ambulatory blood pressure monitoring: 10-year follow-up from the Ohasama study," Journal of the American College of Cardiology, vol. 46, no. 3, pp. 508-515, 2005.

[46] G. Bobrie, G. Chatellier, N. Genes et al., "Cardiovascular prognosis of "masked hypertension" detected by blood pressure self-measurement in elderly treated hypertensive patients," Journal of the American Medical Association, vol. 291, no. 11, pp. 1342-1349, 2004.

[47] K. Eguchi, "Tom Pickering as a clinicalal scientist: masked hypertension," Blood Pressure Monitoring, vol. 15, pp. 85-89, 2010.

[48] C. Cuspidi, S. Meani, C. Valerio, V. Fusi, and A. Zanchetti, "Nocturnal non-dipping pattern in untreated hypertensives at different cardiovascular risk according to the $2003 \mathrm{ESH} / \mathrm{ESC}$ guidelines," Blood Pressure, vol. 15, no. 1, pp. 37-44, 2006.

[49] K. Stolarz, J. A. Staessen, and E. T. O’Brien, "Night-time blood pressure: dipping into the future?" Journal of Hypertension, vol. 20, no. 11, pp. 2131-2133, 2002.

[50] G. Mancia, G. Parati, M. Di Rienzo, and A. Zanchetti, "BP variability," in Handbook of Hypertension, A. Zanchetti and G. Mancia, Eds., vol. 17 of Pathophysiology of Hypertension, pp. 169-177, Elservier Science, Amsterdam, The Netherlands, 1997.

[51] G. Parati and H. Ibsen, "Twenty-four-hour ambulatory blood pressure profiles of high-risk patients in general practice: data from an ambulatory blood pressure monitoring registry," Journal of Hypertension, vol. 25, no. 5, pp. 929-933, 2007.

[52] A. De La Sierra, J. Redon, J. R. Banegas et al., "Prevalence and factors associated with circadian blood pressure patterns in hypertensive patients," Hypertension, vol. 53, no. 3, pp. 466472, 2009.

[53] M. Gorostidi, J. Sobrino, J. Segura et al., "Ambulatory blood pressure monitoring in hypertensive patientswith high 
cardiovascular risk: a cross-sectional analysis of a 20.000patients database in Spain," Journal of Hypertension, vol. 25, pp. 977-984, 2007.

[54] Y. Imai, K. Nagai, M. Sakuma et al., "Ambulatory blood pressure of adults in Ohasama, Japan," Hypertension, vol. 22, no. 6, pp. 900-912, 1993.

[55] G. Bertinieri, G. Grassi, P. Rossi et al., "24-Hour blood pressure profile in centenarians," Journal of Hypertension, vol. 20, no. 9, pp. 1765-1769, 2002.

[56] M. Kikuya, T. Ohkubo, K. Asayama et al., "Ambulatory blood pressure and 10-year risk of cardiovascular and noncardiovascular mortality: the Ohasama study," Hypertension, vol. 45, no. 2, pp. 240-245, 2005.

[57] K. Kario, T. G. Pickering, Y. Umeda et al., "Morning surge in blood pressure as a predictor of silent and clinical cerebrovascular disease in elderly hypertensives: a prospective study," Circulation, vol. 107, no. 10, pp. 1401-1406, 2003.

[58] M. Kikuya, A. Hozawa, T. Ohokubo et al., "Prognostic significance of blood pressure and heart rate variabilities: the Ohasama Study," Hypertension, vol. 36, no. 5, pp. 901-906, 2000.

[59] D. Sander, C. Kukla, J. Klingelhöfer, K. Winbeck, and B. Conrad, "Relationship between circadian blood pressure patterns and progression of early carotid atherosclerosis: a 3year follow-up study," Circulation, vol. 102, no. 13, pp. 15361541, 2000.

[60] J. D. Mediavilla García, C. Fernández-Torres, A. Arroyo Nieto, M. Expósito Ruiz, and J. Jiménez-Alonso, "Study of blood pressure variability in arterial hypertension and relation with glomerular filtration," Medicina Clinica, vol. 132, no. 5, pp. 180-183, 2009.

[61] P. Verdecchia, C. Borgioni, A. Ciucci et al., "Prognostic significance of blood pressure variability in essential hypertension," Blood Pressure Monitoring, vol. 6, pp. 3-12, 1999.

[62] S. S. Andrade, J. B. Serro-Azul, A. Nussbacher et al., "Daytime systolic blood pressure load and previous stroke predict cardiovascular events in treated octogenarians with hypertension," Journal of the American Geriatrics Society, vol. 58, no. 11, pp. 2232-2234, 2010.

[63] K. C. Johnson, K. L. Margolis, M. A. Espeland et al., "A prospective study of the effect of hypertension and baseline blood pressure on cognitive decline and dementia in postmenopausal women: the Women's Health Initiative Memory Study," Journal of the American Geriatrics Society, vol. 56, no. 8, pp. 1449-1458, 2008.

[64] A. Kanemaru, K. Kanemaru, and I. Kuwajima, "The effects of short-term blood pressure variability and nighttime blood pressure levels on cognitive function," Hypertension Research, vol. 24, no. 1, pp. 19-24, 2001.

[65] Y. Yamamoto, I. Akiguchi, M. Hayashi, T. Ohara, K. Ozasa, and K. Oiwa, "The relationship between 24-hour blood pressure readings, subcortical ischemic lesions and vascular dementia," Cerebrovascular Diseases, vol. 19, no. 5, pp. 302-308, 2005.

[66] I. B. Goldstein, G. Bartzokis, D. Guthrie, and D. Shapiro, "Ambulatory blood pressure and brain atrophy in the healthy elderly," Neurology, vol. 59, no. 5, pp. 713-719, 2002.

[67] Y. Hoshide, K. Kario, J. E. Schwartz, S. Hoshide, T. G. Pickering, and K. Shimada, "Incomplete benefit of antihypertensive therapy on stroke reduction in older hypertensives with abnormal nocturnal blood pressure dipping (extreme-dippers and reverse-dippers)," American Journal of Hypertension, vol. 15, no. 10, part 1, pp. 844-850, 2002.
[68] L. M. Wing, M. A. Brown, L. J. Beilin, P. Ryan, and C. M. Reid, "Reverse white-coat hypertension' in older hypertensives," Journal of Hypertension, vol. 20, no. 4, pp. 639-644, 2002. 


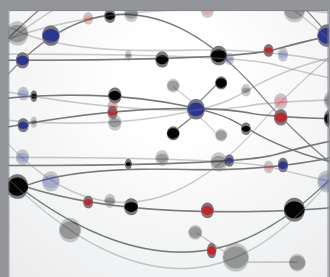

The Scientific World Journal
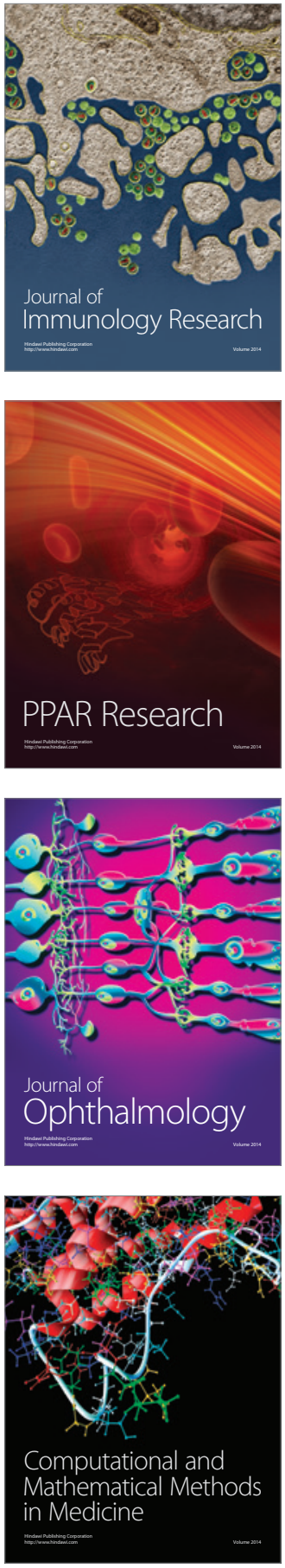

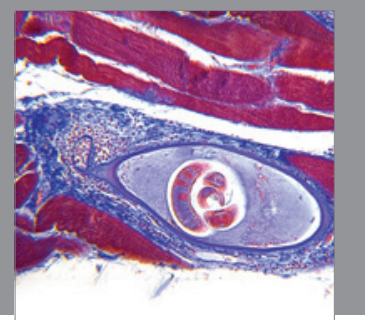

Gastroenterology

Research and Practice
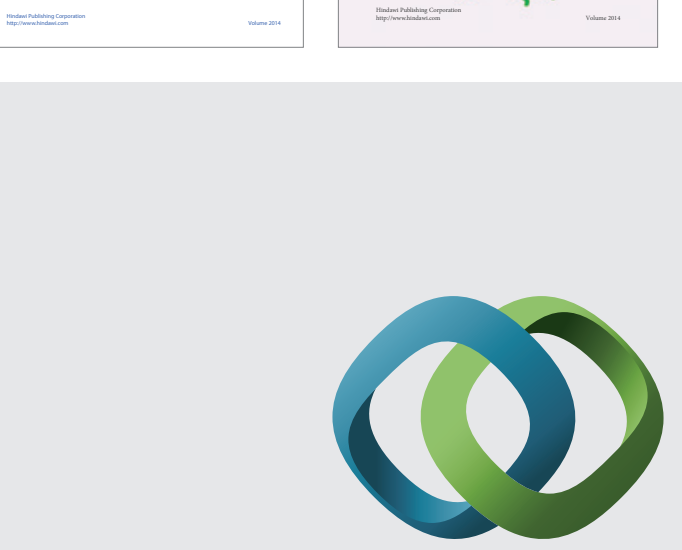

\section{Hindawi}

Submit your manuscripts at

http://www.hindawi.com
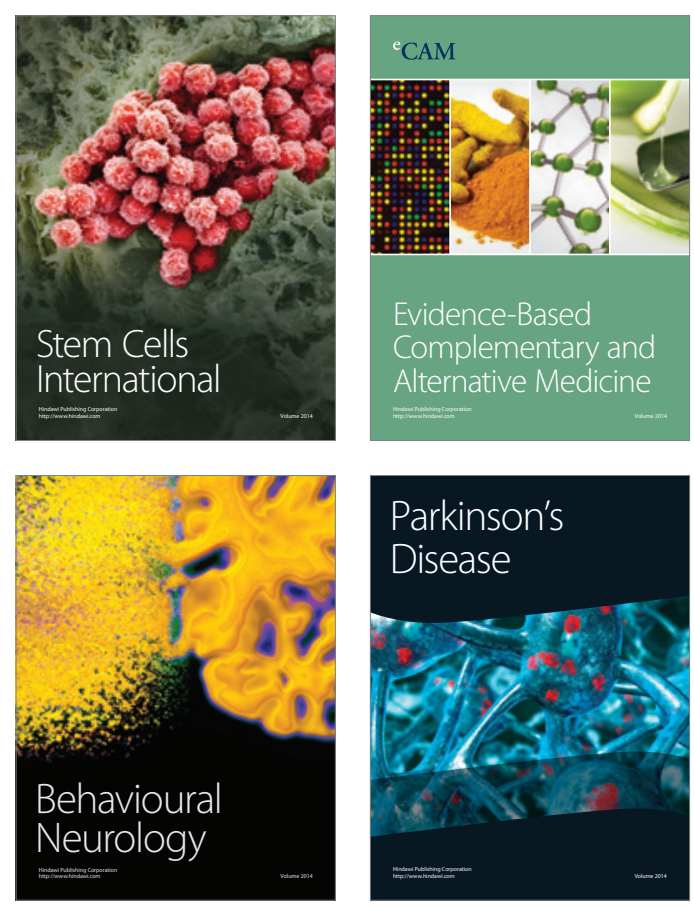

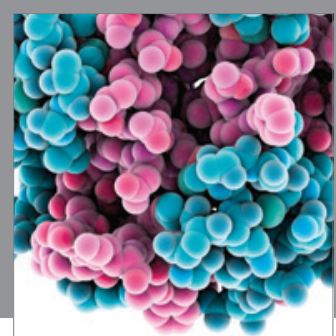

Journal of
Diabetes Research

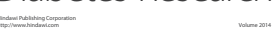

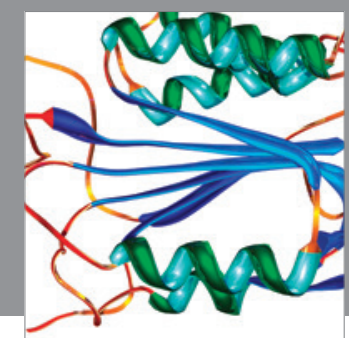

Disease Markers
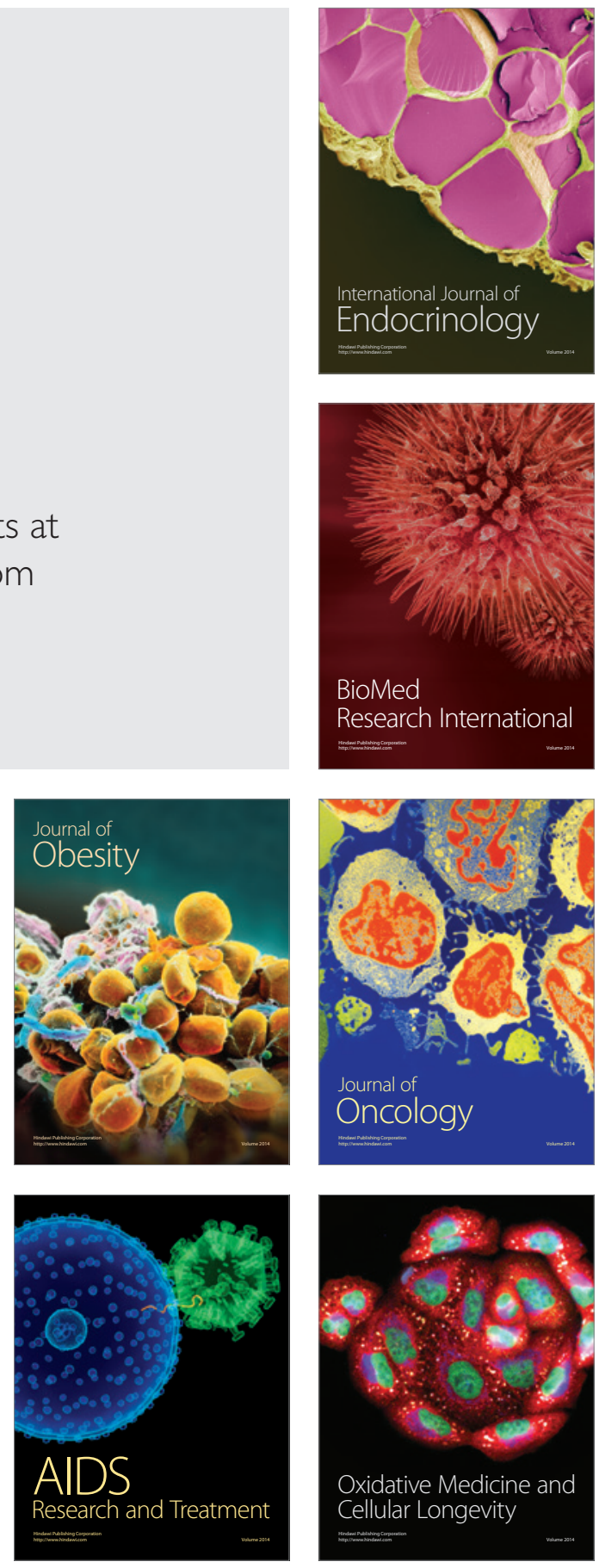